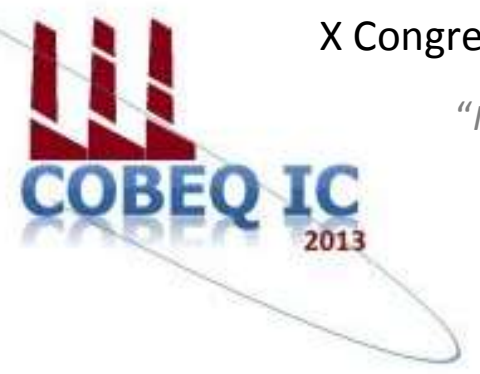

"Influência da pesquisa em Engenharia Química no desenvolvimento tecnológico e industrial brasileiro"

Universidade Federal Rural do Rio de Janeiro Universidade Severino Sombra Vassouras - RJ-Brasil

\title{
PRODUÇÃO DE HIDROGÊNIO ATRAVÉS DO USO DE BACTÉRIA PÚRPURA NÃO SULFUROSA Rhodopseudomona Palustris
}

\author{
L. P. BESSA ${ }^{1}$; F. S. OLIVEIRA ${ }^{2}$; T. V. OLIVEIRA ${ }^{3}$; \\ J. S. FERREIRA ${ }^{4}$; V. L. CARDOSO ${ }^{4} ;$ F. R. X. BATISTA ${ }^{4}$ \\ ${ }^{1}$ Aluna da FEQUI/UFU $\quad{ }^{2}$ Aluno da FEQUI/UFU ${ }^{3}$ Mestranda da FEQUI/UFU $\quad 4$ \\ Professora da FEQUI/UFU \\ Faculdade de Engenharia Química - Universidade Federal de Uberlândia \\ Endereço-UFU, Av.João Naves de Ávila 2121, Santa Mônica, \\ Uberlândia, CEP.38.408-144, MG, \\ email: frxbatista@fequi.ufu.br
}

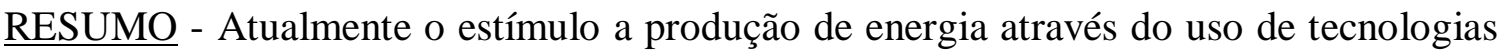
limpas tem sido observado. Neste contexto, destaca-se a obtenção de hidrogênio através de rota biológica a partir do uso de bactérias fotossintetizantes. Processos fotofermentativos utilizando bactérias púrpuras não sulfurosas apresentam-se como uma alternativa atraente para a obtenção deste biocombustível. É neste contexto que este estudo propõe a avaliação da síntese de hidrogênio molecular através do uso de uma cepa pura, a Rhodopseudomona Palustris, cultivada em meio basal RCV e mantida a $30{ }^{\circ} \mathrm{C}$ com intensidade luminosa de 2200 lux e pH inicial de 6,8. O sistema de fotofermentação foi composto por frascos de penicilina de $50 \mathrm{~mL}$ de capacidade, apresentado seringas graduadas de $10 \mathrm{~mL}$ acopladas para a coleta de biogás produzido. Os resultados mostraram que a cepa utilizada foi capaz de produzir $\mathrm{H}_{2}$ quando mantida em meio RCV suplementado com soro de queijo permeado (lactose), extrato de levedura, ambos em concentração $1 \mathrm{~g} / \mathrm{L}$ e glutamato de sódio $2,54 \mathrm{~g} / \mathrm{L}$, atingindo uma produtividade volumétrica de até $87,89 \times 10^{-6} \mathrm{~mol} \mathrm{H}_{2} / \mathrm{L}$.h.
\end{abstract}

Palavras chave: biocombustível, fotofermentação, energia.

\section{INTRODUÇÃO}

Atualmente o uso de combustíveis fósseis tem se tornado cada vez mais restritivo, devido à sua disponibilidade limitada. Acrescenta-se a isso o fato de que os combustíveis fósseis são não renováveis. Diante deste panorama e de todos os problemas ambientais enfrentados reforçou-se a busca por novas fontes energéticas que driblem a forte dependência do petróleo e que assegurem a sustentabilidade do meio ambiente. É neste contexto que o aperfeiçoamento de metodologias para a produção de hidrogênio tem se verificado, uma vez que este se mostra como um combustível altamente energético e tecnologicamente limpo e sustentável. 
Os métodos essenciais para a produção de hidrogênio são a reforma de vapor, usando metano e outros hidrocarbonetos; a oxidação parcial e não catalítica de combustíveis fósseis ou ainda a combinação de ambos. Contudo esses métodos fazem uso dos combustíveis fósseis e existe a necessidade do emprego de altas temperaturas, ou seja, requer elevado gasto energético. Dentre as outras formas de produzir hidrogênio tem-se a produção biológica que pode ser classificada segundo três rotas metabólicas: (i) a biofotólise da água por algas ou cianobactérias, que possui como vantagens a utilização de água que é um substrato abundante e a formação de produtos simples $\left(\mathrm{H}_{2}\right.$ e $\left.\mathrm{CO}_{2}\right)$; (ii) a fermentação de resíduos orgânicos por micro-organismos anaeróbicos ou facultativos, denominada como fermentação escura e (iii) a decomposição de compostos orgânicos por bactérias fotossintéticas, denominada fotofermentação, que pode apresentar conversão completa de ácidos orgânicos a $\mathrm{H}_{2}$ e $\mathrm{CO}_{2}$ (HALLENBECK e GHOSH, 2009).

As bactérias fotossintetizantes púrpuras não sulfurosas (PNS) destacam-se pela habilidade de produzir de forma eficiente o hidrogênio molecular utilizando um amplo espectro de luz. Para tal, se observa o uso de ácidos orgânicos como ácido acético, málico, butírico, etc. Além da iluminação, outro fator essencial é a manutenção de atmosfera inerte e anaeróbia. Tal fato decorre da inativação irreversível que o oxigênio ocasiona na enzima nitrogenase. É importante salientar que no processo metabólico realizado pelos microorganismos para a produção de hidrogênio, a nitrogenase é a principal enzima associada. Esta enzima cataliza reações em meios cuja limitação de nitrogênio se verifica. Neste sentido, é importante que o meio de fermentação não contenha componentes nitrogenados em altas concentrações capazes de inibir a síntese de hidrogênio catalisada pela nitrogenase. Assim, uma estratégia adotada para se impedir a inibição da nitrogenase é a manutenção da razão $\mathrm{C} / \mathrm{N}$ maior que 1 . Nesta condição, evita-se que a fonte de nitrogênio seja consumida antes da fonte de carbono (LÁZARO, 2009).

Segundo OH et. al. (2004), o uso de glutamato de sódio como fonte de nitrogênio apresenta melhores resultados para a produção de hidrogênio em comparação a utilização de sulfato de amônio. Em adição, um teste preliminar realizado por nosso grupo de pesquisa (OLIVEIRA et. al. 2013), no qual ácidos orgânicos foram avaliados para a síntese de $\mathrm{H}_{2}$, indicou que dos ácidos estudados (málico, acético, lático, propiônico e butírico) o que apresentou o maior efeito sobre a produtividade volumétrica para a produção de hidrogênio da cepa Rhodopseudonoma palustris foi o ácido málico. A partir desses resultados, no presente trabalho realizou-se um estudo que abrangeu a realização de sete experimentos univariados empregando a Rhodopseudonoma palustris, agora com o intuito de avaliar a influência da concentração de lactose (presente em elevado percentual no suplemento permeado de soro de leite) como uma potencial fonte de carbono. Concomitantemente, o efeito do tipo de fonte de nitrogênio (glutamato de sódio e sulfato de amônio) para a produção de hidrogênio também foi investigado.

\section{MATERIAIS E MÉTODOS}

\section{Micro-organismo e condições de cultura}

$\mathrm{O}$ micro-organismo Rhodopseudomona palustris foi utilizado ao longo deste estudo. As células foram cultivadas em meio basal RCV (WEAVER et. al., 1975), cuja composição está descrita nas tabelas 1 e 2 . As bactérias foram mantidas a $30{ }^{\circ} \mathrm{C}$ em condição de anaerobicidade e com intensidade luminosa de 2200 lux.

Os testes de fotofermentação foram realizados em duplicata em frascos de penicilina de $50 \mathrm{~mL}$ (volume reacional de 37,5 $\mathrm{mL}$ ), sob luz branca de intensidade inicial de 2200 lux e pH inicial de 6,8. A concentração inicial de células em todos os experimentos foi de $0,1 \mathrm{~g} / \mathrm{L}$. Após o inóculo celular ter sido adicionado aos meios de fermentação, argônio $(99,999 \%)$ foi borbulhado durante três minutos para garantir a condição anaeróbia e só então os frascos de penicilina foram lacrados para a posterior coleta do biogás produzido. O biogás foi coletado em seringas graduadas previamente acopladas a estes frascos.

Sete formulações diferentes, tendo como base o meio RCV, foram empregadas como 
meio de fermentação. Nos ensaios 1 e 4 para a mesma concentração de permeado $(0,5 \mathrm{~g} / \mathrm{L})$ comparou-se a influência do tipo de fonte de nitrogênio. As fontes utilizadas foram glutamato de sódio e sulfato de amônio $(\mathrm{OH}$ et. al., 2004). O mesmo foi feito para os experimentos 2 e 5; 3 e 6 , nas concentrações 1,0 e 2,0 g/L de permeado, respectivamente. Como controle foi realizado um ensaio 7 constituído de meio basal RCV sem suplementação de fonte de nitrogênio e sem a presença de permeado como fonte de carbono. Além disso, extrato de levedura na concentração de $1 \mathrm{~g} / \mathrm{L}$ foi adicionado aos experimentos, exceto para o ensaio controle.

Tabela 1 - Componentes do meio RCV

\begin{tabular}{|l|c|}
\hline \multicolumn{1}{|c|}{ Reagente } & $\begin{array}{c}\text { Concentração } \\
(\mathbf{g} / \mathbf{L})\end{array}$ \\
\hline Ácido Málico & 4,02 \\
\hline $\mathrm{KH}_{2} \mathrm{PO}_{4}$ & 0,60 \\
\hline $\mathrm{K}_{2} \mathrm{HPO}_{4}$ & 0,90 \\
\hline $\mathrm{MgSO}_{4} \cdot 7 \mathrm{H}_{2} \mathrm{O}$ & 0,12 \\
\hline $\mathrm{CaCl}_{2} \cdot 2 \mathrm{H}_{2} \mathrm{O}$ & 0,075 \\
\hline $\mathrm{Na}_{2}$ EDTA.2 $\mathrm{H}_{2} \mathrm{O}$ & 0,02 \\
\hline Micronutrientes & $1 \mathrm{~mL}$ \\
\hline Tiamina & 0,001 \\
\hline$\left(\mathrm{NH}_{4}\right)_{2} \mathrm{SO}_{4}$ & 1 \\
\hline
\end{tabular}

Tabela 2 - Composições da solução de micronutrientes utilizada no meio RCV

\begin{tabular}{|l|c|}
\hline \multicolumn{1}{|c|}{ Reagente } & $\begin{array}{c}\text { Concentração } \\
\text { (g/L) }\end{array}$ \\
\hline $\mathrm{H}_{3} \mathrm{BO}_{3}$ & 2,8 \\
\hline $\mathrm{MnSO}_{4} \mathrm{H}_{2} \mathrm{O}$ & 1,59 \\
\hline $\mathrm{NaMoO}_{4} 2 \mathrm{H}_{2} \mathrm{O}$ & 0,75 \\
\hline $\mathrm{ZnSO}_{4} 7 \mathrm{H}_{2} \mathrm{O}$ & 0,24 \\
\hline $\mathrm{CaCl}_{2} \cdot 2 \mathrm{H}_{2} \mathrm{O}$ & 0,075 \\
\hline $\mathrm{CuCl}_{2} 2 \mathrm{H}_{2} \mathrm{O}$ & 0,05 \\
\hline
\end{tabular}

\section{Análises Físico-Químicas}

A determinação da concentração PNS foi realizada através do método gravimétrico. Para tal, uma curva de calibração (Figura 1) foi obtida. Na determinação da curva, a densidade óptica a $660 \mathrm{~nm}\left(\mathrm{OD}_{660}\right)$ foi medida em um espectofotômetro (GENESYS) e convertida em g/L pela equação de correlação entre $\mathrm{OD}_{660}$ e $\mathrm{g}$ de $\mathrm{PNS} / \mathrm{L}$.

Já a determinação da composição do biogás foi determinada em um cromatógrafo a gás GC $17^{\mathrm{a}}$ Shimadzu, com detector de condutividade térmica (TCD), coluna capilar Carboxen 1010 (comprimento de $30 \mathrm{~m}$, diâmetro interno $0,53 \mathrm{~mm}$ ), temperatura do injetor $230{ }^{\circ} \mathrm{C}$, temperatura da coluna $30{ }^{\circ} \mathrm{C}$ e temperatura do detector $230{ }^{\circ} \mathrm{C}$, utilizando argônio como gás de arraste.

\section{RESULTADOS E DISCUSSÃO}

A Figura 1 apresenta a curva de calibração obtida para o sistema avaliado e que promoveu a determinação da concentração celular durante a fermentação.

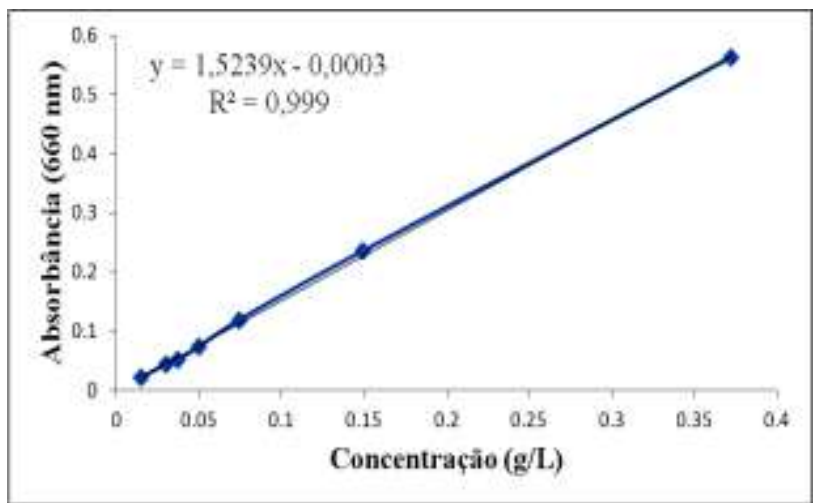

Figura 1 - Curva de Calibração utilizada na determinação da concentração celular

A Tabela 3 apresenta composições dos meios de fermentação avaliados no estudo e os resultados obtidos em termos de concentração celular $(\mathrm{g} / \mathrm{L})$, produtividade em hidrogênio $\left(10^{-6} \mathrm{~mol} \mathrm{H}_{2} / \mathrm{L} . \mathrm{h}\right)$ e rendimento $\left(10^{-2} \mathrm{~mol}\right.$ $\mathrm{H}_{2}$ /células). Os dados mostraram que, em geral, a produtividade foi maior quando o glutamato de sódio foi usado como fonte de nitrogênio em contraste ao uso do sulfato de amônio. A condição que resultou em maior produtividade $\left(87,89 \times 10^{-6} \mathrm{~mol} \mathrm{H}_{2} /\right.$ L.h $)$ foi constituída pelo meio RCV contendo glutamato de sódio como fonte de nitrogênio $(2,54 \mathrm{~g} / \mathrm{L})$, extrato de levedura $(1,0 \mathrm{~g} / \mathrm{L})$ e permeado de soro de leite como fonte de carbono (2,0 g/L). Na Tabela 3 observa-se ainda que dos ensaios de 1 a 3 , com glutamato de sódio como fonte de nitrogênio $(2,54 \mathrm{~g} / \mathrm{L})$, a maior concentração celular observada $(0,84$ $\mathrm{g} / \mathrm{L})$ foi obtida no ensaio 2, constituído também por permeado de soro e leite $(1,0 \mathrm{~g} / \mathrm{L})$. Esses dados permitem a constatação de que nos ensaios com glutamato de sódio como fonte de nitrogênio, o aumento na 
concentração da fonte de carbono (permeado de soro de leite) utilizando glutamato de sódio, promoveu um incremento na produtividade e no rendimento de célula em hidrogênio, embora o mesmo não se possa dizer para a concentração celular.

Tabela 3 - Efeito da lactose e da fonte de nitrogênio no cultivo da cepa Rhodopseudomona palustris produtora de hidrogênio. Extrato de levedura $(1 \mathrm{~g} / \mathrm{L})$ foi suplementado aos ensaios de 1 a 6. O tempo de fermentação foi de cinco dias.

\begin{tabular}{|c|c|c|c|c|c|}
\hline Ensaio & $\begin{array}{c}\text { Permeado } \\
\text { de soro de } \\
\text { leite } \\
(\mathrm{g} / \mathrm{L})\end{array}$ & $\begin{array}{l}\text { Concentração da } \\
\text { fonte de } \\
\text { nitrogênio }(g / L)\end{array}$ & $\begin{array}{c}\text { Concentração } \\
\text { celular }(g / L)\end{array}$ & $\begin{array}{c}\text { Produtividade } \\
\left(10^{-6} \mathrm{~mol}\right. \\
\left.\mathrm{H}_{2} / \text { L.h }\right)\end{array}$ & $\begin{array}{c}Y_{\mathrm{H} 2 / \mathrm{X}} \\
\left(10^{-2} \mathrm{~mol}\right. \\
\left.\mathrm{H}_{2} / \text { célula }\right)\end{array}$ \\
\hline \multicolumn{6}{|c|}{ Meio RCV suplementado (glutamato de sódio como fonte nitrogênio) } \\
\hline 1 & 0,5 & \multirow{3}{*}{2,54} & 0,72 & 55,62 & 0,93 \\
\hline 2 & 1,0 & & 0,84 & 78,07 & 1,11 \\
\hline 3 & 2,0 & & 0,77 & 87,89 & 1,37 \\
\hline \multicolumn{6}{|c|}{ Meio RCV suplementado (sulfato de amônio como fonte nitrogênio) } \\
\hline 4 & 0,5 & \multirow{3}{*}{1,00} & 0,68 & 50,23 & 0,88 \\
\hline 5 & 1,0 & & 0,73 & 71,15 & 1,17 \\
\hline 6 & 2,0 & & 0,92 & 77,12 & 1,01 \\
\hline \multicolumn{6}{|c|}{ Meio RCV basal (controle) } \\
\hline 7 & 0 & 1,00 & 0,45 & 17,58 & 0,47 \\
\hline
\end{tabular}

Para os ensaios com sulfato de amônio como fonte de nitrogênio $(1,0 \mathrm{~g} / \mathrm{L})$, a maior produtividade $\left(77,12 \times 10^{-6} \mathrm{~mol} \mathrm{de} \mathrm{H}_{2} /\right.$ L.h $)$ e maior concentração celular $(0,92 \mathrm{~g} / \mathrm{L})$ obtidos foram no ensaio 6 , constituído por permeado de soro de leite $(2,0 \mathrm{~g} / \mathrm{L})$ e extrato de levedura $(1,0 \mathrm{~g} / \mathrm{L})$. Estes dados nos permitem constatar que com sulfato de amônio sendo utilizado como fonte de nitrogênio, um aumento na concentração da fonte de carbono (permeado de soro de leite) também promoveu um incremento na produtividade, porém nestes, diferentemente dos ensaios utilizando glutamato de sódio, este aumento na concentração da fonte de carbono também promoveu aumento na concentração celular, embora o mesmo não se possa dizer para o rendimento de célula.

É importante salientar que todas as formulações de 1 a 6 resultaram em valores superiores àquela observada no ensaio controle, em termos de produtividade, rendimento e concentração final de células. A produção de hidrogênio utilizando Rhodopseudomona palustris foi investigada por Tian et al. (2009) utilizando um fotobiorreator em que glicose foi usada como substrato. Sob as melhores condições de concentração de glicose $(0,12 \mathrm{M}), \mathrm{pH}(7)$ e da temperatura do líquido afluente $\left(25^{\circ} \mathrm{C}\right)$, o rendimento foi de 0,2 moles de hidrogênio $\mathrm{H}_{2} /$ mol glicose.

AFSAR et. al. (2011) também avaliaram a produção de hidrogênio pela Rhodopseudomona palustris. A fotofermentação foi realizada utilizando como substrato o efluente da fermentação escura contendo acetato $(114 \mathrm{mM})$, ácido lático (6 $\mathrm{mM})$, glicose $(20 \mathrm{mM})$ e $\mathrm{NH}_{4} \mathrm{Cl}(1 \mathrm{mM})$, sendo que este efluente foi diluído três vezes. A produtividade encontrada foi de $330 \times 10^{-6}$ mol de $\mathrm{H}_{2} /$ L.h, valor no qual está acima do valor máximo encontrado neste estudo $\left(87,89 \times 10^{-6} \mathrm{~mol} \mathrm{de} \mathrm{H}_{2} /\right.$ L.h $)$. Este resultado pode, em parte, ser explicado pela diferença nos parâmetros como modo de operação, configuração do biorreator, $\mathrm{pH}$, temperatura, fotoperíodo e intensidade luminosa também 
podem afetar a produtividade da fotofermentação.

\section{CONCLUSÃO}

Conclui-se deste trabalho que a lactose obtida do permeado de soro de leite aumenta a produtividade volumétrica em hidrogênio da cepa Rhodopseudomona Palustris e que o glutamato de sódio é a fonte de nitrogênio do meio RCV que mais influenciou para o aumento desta variável.

\section{NOMENCLATURA}

A Tabela 4 sumariza os símbolos utilizados neste estudo.

Tabela 4 - Simbologia empregada no estudo

\begin{tabular}{|c|l|}
\hline Sigla & \multicolumn{1}{|c|}{ Significado } \\
\hline OD $_{660}$ & $\begin{array}{l}\text { Densidade Óptica com comprimento } \\
\text { de onda de 660nm }\end{array}$ \\
\hline PNS & Bactérias Púrpuras Não Sulfurosas \\
\hline TCD & Detector de Condutividade Térmica \\
\hline
\end{tabular}

\section{REFERÊNCIAS}

AFSAR, N.; ÖZGÜR , E.; GÜRGAN, M.; AKKÖSE, S.; YÜCEL, M.; GÜNDÜZ, U.; EROGLU, I. Hydrogen productivity of photosynthetic bacteria on dark fermenter effluent of potato steam peels hydrolysate. International Journal of Hydrogen Energy.v.36.p.432-438, 2011.

HALLENBECK, P. C.; GHOSH, D. Advances in fermentative biohydrogen. Trends biotechnol., v. 05, n. 27, p.287-297, 2009.

LAZARO, C. Z. Obtenção e Caracterização Filogenética de Consórcio de Bactérias Fototrópicas Púrpuras Não-Sulfurosas Consumidoras de Ácidos Orgânicos Visando a Produção de Hidrogênio em Reator Anaerobio de Batelada. Dissertação de Mestrado, Escola de Engenharia de São Carlos, 2009.

OH, Y.; SEOL, E.; KIM, M.; PARK, S. Photoproduction of hydrogen from acetate by a chemoheterotrophic bacteria Rhodopseudomonas palustris P4.Int. J.
Hydrogen Energ., n. 29, p.1115-1121, 2004.

OLIVEIRA, T.V.; OLIVEIRA, F. S.; SOUSA, T. M.; FERREIRA, J. S.; BATISTA, F. R. X.; CARDOSO, V. L. Avaliação da influência de ácidos orgânicos na produção de biohidrogênio por fotofermentação. Simpósio Nacional de Fermentações (SINAFERM), Foz do Iguaçú, 2013.

TIAN. X.; LIAO. Q.; ZHU. X.; WANG. Y., ZHANG. P.; LI. J.; WANG. H. Characteristics of a biofilm photobioreactor as applied to photohydrogen production. Bioresource Technology, v. 101, p. 977-983, 2010.

WEAVER, P.F.; WALL, J.D.; GEST, H. Characterization of Rhodopseudomonas capsulata. Arch. microbiol. 1975, Volume 105, Issue 1, pp 207-216.

\section{AGRADECIMENTOS}

Os autores agradecem a Universidade Federal de Uberlândia e a Faculdade de Engenharia Química pela oportunidade em realizar este trabalho. Agradecem também ao apoio financeiro da FAPEMIG, da Vale S.A., do CNPq e da CAPES. 